\title{
Comparison Study of Heptylbenzene and Hexylbenzene Decomposition under Supercritical Water
}

\author{
Pradip C. Mandal, Sujan Chowdhury, and Mitsuru Sasaki
}

\begin{abstract}
The world reserves of conventional light oils are decreasing and being replaced by an increasing amount of heavy oils. Heptylbenzene (HPB) and hexylbenzene (HXB) are compounds that are also present in heavy oils. This study is aimed at comparing the supercritical hydrolysis reaction of HPB and HXB producing low molecular weight hydrocarbons. The dramatic change in the ionic product and the dielectric constant of water under supercritical conditions makes it an acid or a base catalyst. In this study, water was used without any catalyst. The reaction was carried out in an $8.8 \mathrm{~mL}$ batch type reactor fabricated from Hastelloy $\mathrm{C}-276$ whose respective design temperature and pressure was $500^{\circ} \mathrm{C}$ and $50 \mathrm{MPa}$. The comparison study on the ability of supercritical water (SCW) to decompose HPB and HXB were studied at temperatures of $450-475^{\circ} \mathrm{C}$ and water partial pressure (WPP) of $35 \mathrm{MPa}$. The experimental results show that conversion as well as production of low molecular weight compounds was high at water to oil ratio of 10 , a reaction time of $60 \mathrm{~min}$ and a temperature of $475^{\circ} \mathrm{C}$. The supercritical water was found to be potential to convert the heavy oils into the lighter oils without the addition of any catalyst.
\end{abstract}

Index Terms-Batch reactor, heavy oil, heptylbenzene, hexylbenzene, supercritical water.

\section{INTRODUCTION}

The upgrading of heavy oils will continue to increase in importance as changes in crude oil availability cause a shift toward heavier crudes [1]-[8]. The coking process and catalytic hydrogenation process are the traditionally used upgrading process [1], [9]. Catalytic pyrolysis of heavy oil has attracted great interests to produce low molecular weight hydrocarbons. In catalytic pyrolysis, the reactions are coupled catalytically and thermally [10]. The heavy oil contains significant quantities of metals, sulfur and nitrogen heteroatoms. The main obstacle to use catalytic process is that metals and asphaltenic molecules accumulate on catalysts surface during the process causing permanent catalyst deactivation [11]. In addition, high molecular-weight compounds, which are difficult to crack, and char formation are also observed during cracking making the process non-profitable [9]. Traditional cracking can be probably replaced by supercritical hydrothermal cracking to overcome the difficulties of pyrolysis.

Manuscript received May 15, 2015; revised July 14, 2015. This work was supported by the Global COE program on Global Initiative Centre for Pulsed Power Engineering, Japan.

P. C. Mandal and S. Chowdhury are with the Department of Chemical Engineering, Universiti Teknologi Petronas, Bandar Seri Iskandar, 31750 Tronoh, Perak, Malaysia (e-mail: pradip.mandal@petronas.com.my, sujan.chowdhury@petronas.com.my).

M. Sasaki is with the Institute of Pulsed Power Science, Kumamoto University, 2-39-1 Kurokami, Kumamoto 860-8555, Japan (e-mail: msasaki@kumamoto-u.ac.jp).
Supercritical water (SCW), water whose temperature and pressure is above the critical point $\left(374^{\circ} \mathrm{C}\right.$, and $\left.22.1 \mathrm{MPa}\right)$, is a highly diffusive steam and can be miscible with gases and hydrocarbons to form a homogeneous mixture [12]. The supercritical water oxidation (SCWO) processes have successful evidence for treating organic wastes [13] using solubility effect of SCW. Literature revealed that the ion product of water increases significantly at high temperatures and pressures. The dielectric constant of SCW varies between 2 and 30. This range includes the dielectric constants of nonpolar solvents, such as, hexane whose dielectric constant is close to 1.8 and those of polar solvents, such as, methanol whose dielectric constant is close to 32.6. Due to this dramatic variability in the ion product and dielectric constant, SCW possesses acidic or base effects on chemical reactions [14] and has attracted much attention as a clean and efficient reaction medium [15] for conversion of organic compounds. It also inhibits the cracking of bitumen to lower molecular weight substance [16]. SCW also acts as a hydrogen donor [1] and water molecules often take part as collision partners [12]. Because of its special properties, subcritical water and SCW has in recent years been considered an effective reaction medium in organic synthesis, fuel processing, biomass conversion, hydrogen production, upgrading of heavy oils and so on [3].

Very recently, SCWO [9], [13], [17] was introduced as an important application of reactions in hydrothermal system, water at high temperature and pressure. Previous studies on SCWO have focused only on heteroatom-containing organic compounds [9]. Sato et al. in 2003 [12] discovered that SCW is favorable for the decomposition of alkylphenols in water. Very few studies have been conducted on the pyrolysis of hydrocarbons in SCW by Houser et al. [18] in 1986, Hirth and Franck [19] in 1993, Arai and Adschiri [20] in1999, Ederer et al. [21] in 1999, Savage [22] in 1999, Ding et al. [23] in 2006 and Mandal et al. [9] in 2011. These studies showed that water had no significant effect on the pyrolysis of alkylbenzenes. Nevertheless, the cage effect (the manner in which the properties of a molecule are affected by its surroundings), water attack on the molecular species or thermolysis, and the change in the phase behavior would decide the role of SCW on the alkylbenzenes decomposition reaction [9]. Mandal et al. conducted kinetic and simulation study of heptylbenzene (HPB) decomposition in SCW [9], [24]. Their study shows that HPB decomposed under SCW producing low molecular weight hydrocarbons and suppressing coke formation.

The reactions of alkylbenzene both in neat pyrolysis and in SCW are essential to understand the effect of water on the decomposition of alkylbenzene [9]. Long chain n-alkylbenzenes present in heavy crude oil or oil sands are 
the dimpliest chemical models of alkylaromatic moieties. In this paper, comparison reactions of HPB and hexylbenzene (HXB) both in the absence and in the presence of SCW are carried out to understand the effect of SCW on hydrolysis reaction.

\section{EXPERIMENTAL SECTION}

\section{A. Materials and Equipment}

Commercially available HPB (purity: $99.7 \%$ by GC), HXB (purity: $99.9 \%$ by GC), and acetone were purchased FROM Wako Pure Chemicals Ltd. and used as received without further treatment.

\section{B. Materials and Equipment}

All experiments were carried out in an $8.8 \mathrm{~mL}$ batch reactor fabricated from hastelloy $\mathrm{C}-276$. The reactor was designed and tested by AKICO (Tokyo, Japan) for a maximum temperature of $500^{\circ} \mathrm{C}$ and maximum pressure of $50 \mathrm{MPa}$. An electric furnace also made by AKICO was used to heat up the reactor isothermally during potential experiments.

\section{Experimental Procedure}

Approximately $2.0 \mathrm{~mL} \mathrm{HPB}$ or $\mathrm{HXB}$ and $0-2.0 \mathrm{~mL}$ distilled water were taken in the batch type reactor for pyrolysis and hydrolysis reactions. The amount of water loaded into the reactor was moderated to control water partial pressure (WPP) at constant temperature and reactor volume. The software, Water I, v.3.3, produced by Summit Research Corporation (1996) was used to calculate the amount of water required by fixing the temperature and WPP. The reactor was reassembled and argon gas was used to purge the reactor to remove gaseous portion from the reactor. Then the reactor was loaded into an electric furnace made by AKICO (Tokyo, Japan), that was pre-heated to the reaction operating temperature, to heat up. During each run, the reactor was shaken by front and back motion at approximately 70 cycles per minute, a rate sufficient to cause the reactor interior temperature to increase quickly. After a specific reaction period, the furnace was stopped, and quenched in water bath for an hour. The reactor was then open and water was separated using a separating funnel. Finally, the reaction products were collected by washing with acetone.

\section{Analytical Procedure}

Qualitative analysis of the reaction liquid mixture was done using the GC/MS method and quantitative analysis was carried out by GC-FID. The GC/MS column was a non-polar HP-1MS capillary column, $30 \mathrm{~m}$ long by $0.32 \mathrm{~mm}$ diameter. The GC-FID measurement was carried out using Shimadzu GC 2014 instrument using the same temperature program used in GC/MS. The samples were diluted by adding acetone for GC/MS and GC-FID analysis. Conversion was defined as the amount of reactant reacted divided by the amount of reactant loaded.

\section{RESUlTS AND DiSCUSSION}

HPB is a colorless liquid that contain seven carbon atoms in its side chain. HXB containing six carbon atoms in its side chain is also a colorless liquid. The color of liquid product obtained by pyrolysis and supercritical hydrolysis turned from yellowish to reddish over increasing reaction time and temperature. Though HPB and HXB were immiscible with water, they dissolved in SCW by decomposition. Reaction liquid products and gaseous products were obtained at the end of specific reaction time both in HPB and HXB decomposition. Reaction liquid products were analyzed which comprise light hydrocarbons and heavy hydrocarbons. Productions of light hydrocarbons dominated in the yield of products. The reaction of HPB and HXB both in the absence and in the presence of SCW involved decomposition to short chain alkylbenzenes by continuous specific scission, the fragmentation of terminal peripheral alkyl substituent, and random scission, the fragmentation of alkyl substituent at different parts of side chain, phenomena. In addition, naphthalene produced by ring formation reaction and heavier molecular compounds produced by addition reaction in side chain of benzene via secondary reactions of scission products.

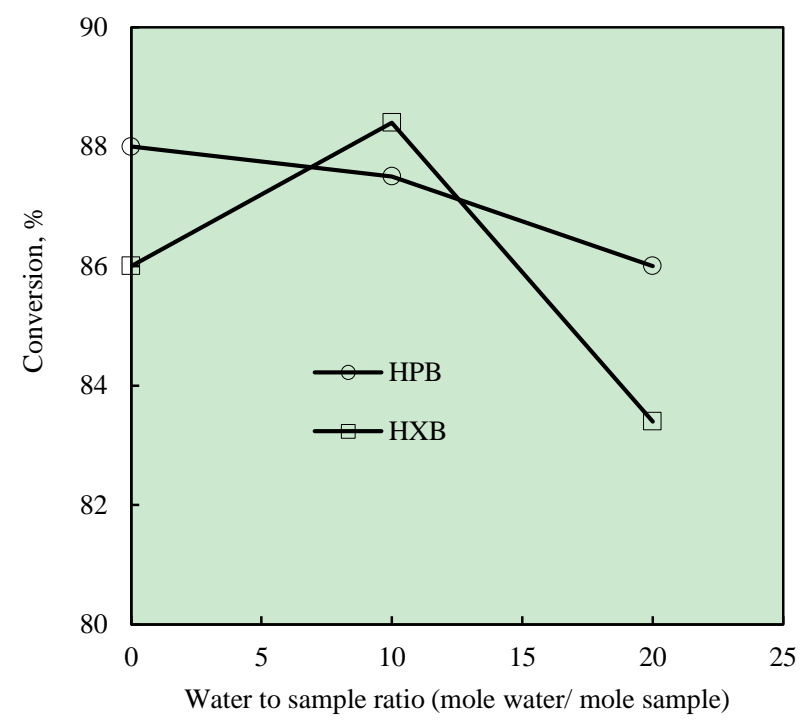

Fig. 1. Conversion of HPB and HXB.

The conversion versus water to sample (HPB or HXB) ratio plot of HPB and $\mathrm{HXB}$ supercritical hydrolysis is displayed in Fig. 1. It was found that average HPB conversion was high compared to $\mathrm{HXB}$ conversion. In addition, conversion of HPB and HXB depends on molar ratio of water to sample at a constant temperature of $450^{\circ} \mathrm{C}$. Experimental results show that HXB conversion was high at water to HXB ratio of 10 . On the other hand, HPB conversion slowly decreased by the action of SCW. Mandal et al. [9] revealed that HPB conversions are affected very slightly at supercritical condition. Similar results were observed during the reaction with HXB. Mandal et al. in their study of HPB conversion in SCW discovered that SCW had a negligible influence on the reaction pathways; but it can accelerate phenylolefin and toluene formation path by suppressing the other paths compare to pyrolysis without water. During the HXB conversion in SCW, SCW could suppress precipitationor char formation and the side reactions that produced high molecular weight compounds at high temperatures. This was the good agreement with HPB conversion in SCW.

Golombak and Ineke [25] in 2013 disclosed that the hot 
water can pyrolytically crack the long molecular weight hydrocarbon structures. Literature review revealed that the hydrothermal reaction mechanism depends on water density: the reaction is controlled by the ionic reaction mechanism at high water density and low temperature; whereas the free radical reaction mechanism is prevalent at low water density and high temperature [26], [27]. Thus, reactions of heavy oil with subcritical water can be described by free radical reaction mechanism as presented by Mandal et al. [9]. Weingartner and Franck [28] disclosed that ionic product falls by orders of magnitude at SCW condition, thus is able to produce $\mathrm{H}$ and $\mathrm{OH}$ radicals under experimental conditions.

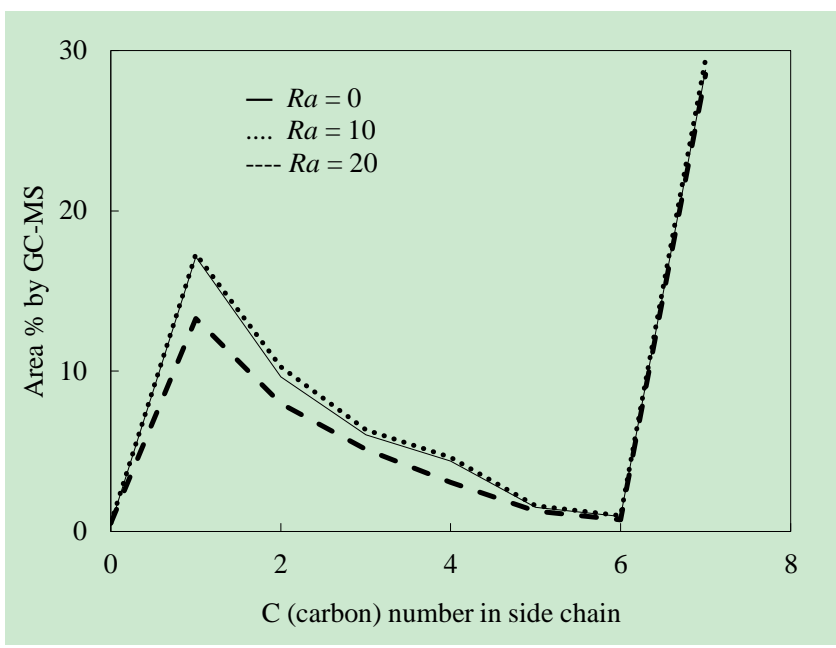

Fig. 2a. Effect of water to oil ratio $(R a)$ for HPB.

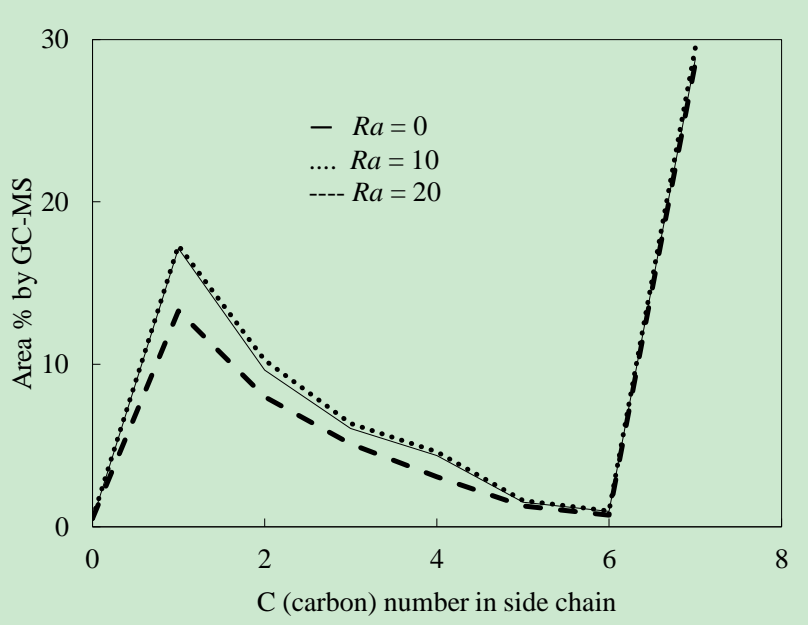

Fig. 2b. Effect of water to oil ratio $(R a)$ for HXB.

Heteroatom containing organics present in the body can react with water via hydrolysis [14], [17], [18]. Moriya and Enomoto [29], Arai and Adschiri [20] and Mandal et al. [9] reported that the effect of SCW on the pure hydrocarbon decomposition is insignificant. Fig. $2 a$ and $2 b$ illustrate the effect of water to oil ratio on HPB and HXB decomposition at a temperature of $450^{\circ} \mathrm{C}$, a pressure of $35 \mathrm{MPa}$ and a reaction time of $60 \mathrm{~min}$ respectively. Toluene was the most abundant product throughout the course of the reaction both in HPB and $\mathrm{HXB}$ decomposition. But production of toluene was high in HPB decomposition indicating the increasing of ring scission reactions. Water to oil ratio 10 had a high capability to produce low molecular weight compound compare to pyrolysis and supercritical hydrolysis at ratio 20 indicating that low ratios can favor the production of low molecular weight compounds.

Fig. $3 \mathrm{a}$ and $3 \mathrm{~b}$ depict the reaction time effect on decomposition of HPB and $\mathrm{HXB}$ at a temperature of $450^{\circ} \mathrm{C}$, a pressure of $35 \mathrm{MPa}$ and reaction time of $60 \mathrm{~min}$ respectively. Scission on long chain alkylbenzenes increased to produce short chain alkylbenzenes with increasing reaction time. Conversion was low at lower reaction time, but it increased with time. Toluene was the dominating liquid products at all reaction time. On the other hand, HPB produced more toluene than HXB indicating the probability of $\mathrm{HXB}$ to produce more gaseous products.

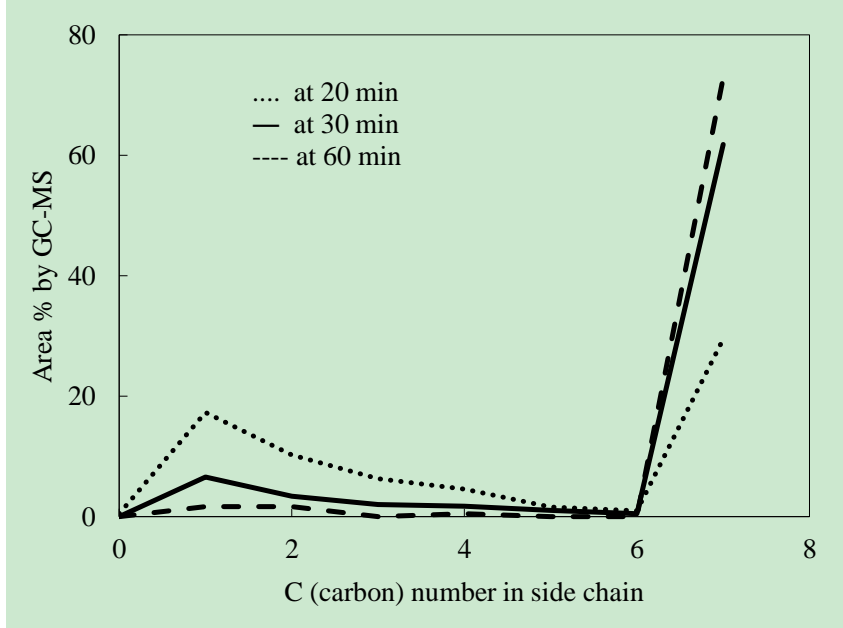

Fig. 3a. Effect of reaction time for HPB.

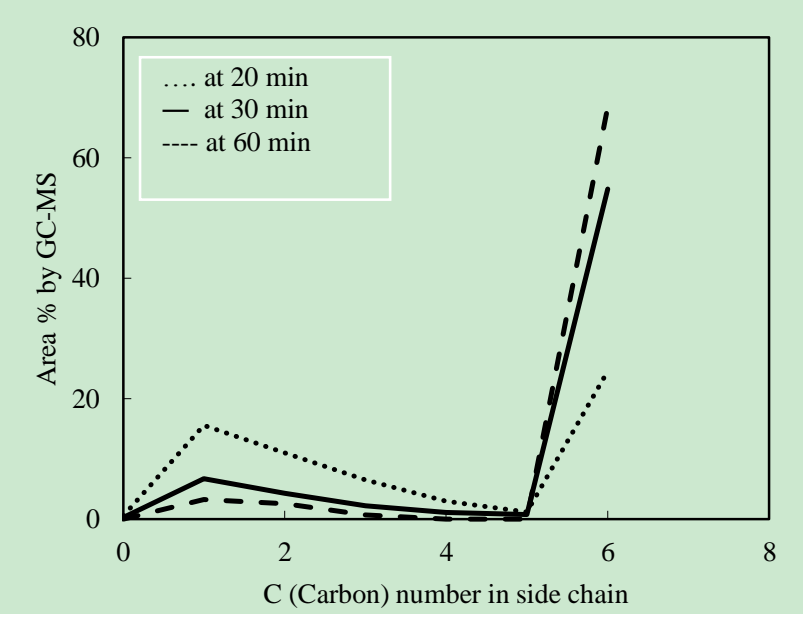

Fig. 3b. Effect of reaction time for HXB.

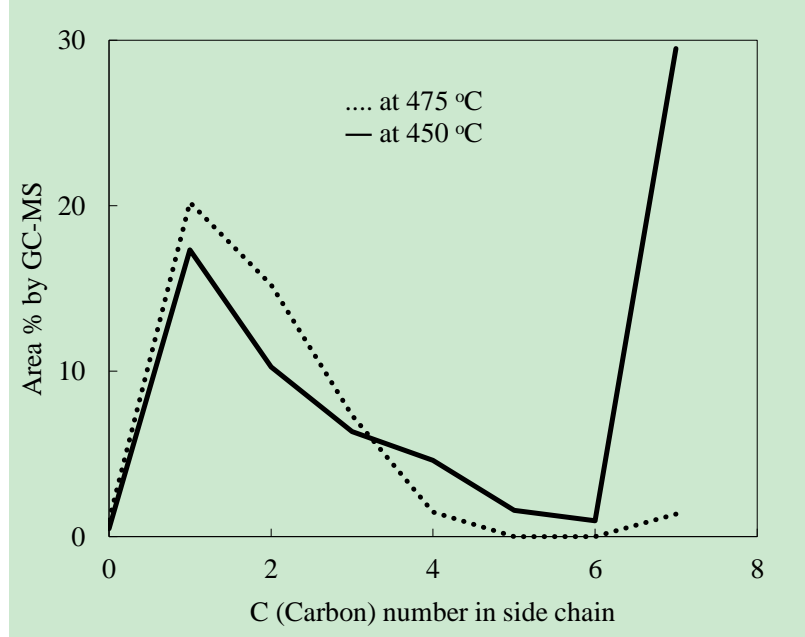

Fig. 4a. Effect of temperature for HPB 


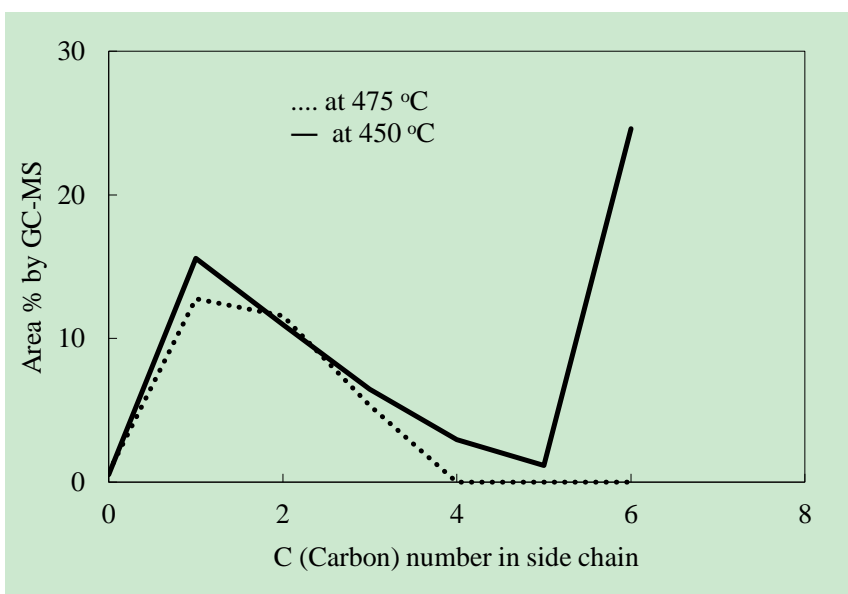

Fig. 4b. Effect of temperature for HXB.

Fig. $4 \mathrm{a}$ and $4 \mathrm{~b}$ show the effect of temperature on decomposition of HPB and HXB at a pressure of $35 \mathrm{MPa}$ and a reaction time of 60 min. During $\mathrm{HXB}$ decomposition, productions of short chain containing compounds were decreased by the action of heat indicating the high production of gases. Thus, short chain alkylbenzene produced more gaseous products than long chain alkylbenzene at extreme reaction conditions. Toluene was found to be a stable compound during the course of reactions.

\section{CONCLUSIONS}

This study has shown that both HPB and HXB decomposed into light hydrocarbons; heavy hydrocarbons and gases. The basic reaction mechanisms of both HPB and HXB decomposition were shortening and rearranging side chain of benzene, ring formation and addition reaction in side chain of benzene. The average HPB conversion was high compared to the average $\mathrm{HXB}$ conversion though the product distribution was sensitive to water to oil ratios. But, low water to oil ratio favored the production of low molecular weight compounds. Conversion as well as production of low molecular weight compounds was high at a reaction time of $60 \mathrm{~min}$ and a temperature of $475^{\circ} \mathrm{C}$. Nevertheless, HPB and HXB decomposed successfully under SCW without catalyst at temperatures of $450-475^{\circ} \mathrm{C}$ and a pressure of $35 \mathrm{MPa}$ producing low molecular weight hydrocarbons.

\section{ACKNOWLEDGMENT}

This work was supported by the Global COE program on Global Initiative Centre for Pulsed Power Engineering, Japan.

\section{REFERENCES}

[1] M. Watnabe, S. Kato, S. Ishizeki, H. Inomata, and R. L. Smith Jr., "Heavy oil upgrading in the presence of high density water: Basic study," J. Supercrit. Fluids, vol. 53, pp. 48-52, 2010.

[2] T. Adschiri, "Supercritical water up-grading of heavy oils," J. Jpn. Inst. Energy, vol. 88, No. 3, pp. 172-175, 2009.

[3] P. C. Mandal, Wahyudiono, M. Sasaki, and M. Goto, "Non-catalytic vanadium removal from vanadyl etioporphyrin (VO-EP) using a mixed solvent of supercritical water and toluene: A kinetic study," Fuel, vol. 92, pp. 288-294, 2012.

[4] C. W. Hung and J. Wei, "The kinetics of porphyrin hydrodemetallation. 1. Nickel compounds," Ind. Eng. Chem. Process Des. Dev., vol. 19, pp. 250-256, 1980
[5] C. W. Hung, and J. Wei, "The kinetics of porphyrin hydrodemetallation. 1. Vanadyl compounds," Ind. Eng. Chem. Process Des. Dev., vol. 19, pp. 257-263, 1980.

[6] B. J. Smith and J. Wei, "Deactivation in catalytic hydrodemetallation 1 Model compound kinetic studies," J. Catal., vol. 132, pp. 1-20, 1991.

[7] A. J. Garcia-Lopez, R. Cuevas, J. Ramirez, J. Ancheyta, A. A. Vargas-Tah, R. Naves, and A. Gutierrez-Alejandre, "Hydrodemetallation (HDM) kinetics of Ni-TPP over Mo/Al2O3-TiO2 catalyst," Catal. Today, vol. 107-108, pp. 545-550, 2005.

[8] G. P. Dechaine and M. R. Gray, "Chemistry and associated of vanadium compounds in heavy oil and bitumen, and implications for their selective removal," Energy Fuels, vol. 24, pp. 2795-2808, 2010.

[9] P. C. Mandal, T. Shiraishi, Wahyudiono, M. Sasaki, and M. Goto, "Kinetics and reaction pathways for heptylbenzene decomposition in supercritical water," J. Chem. Eng. Jpn., vol. 44, no. 7, pp. 486-493, 2011.

[10] X. Meng, C. Xu, J. Gao, and L. Li, "Seven-lump kinetic model for catalytic pyrolysis of heavy oil," Catalysis Communications, vol. 8, pp. 1197-1201, 2007.

[11] R. M. Filho and M. F. Sugaya, "A computer aided tool for heavy oil thermal cracking process simulation," Comput. Chem. Eng., vol. 25, pp. 683-692, 2001.

[12] T. Sato, T. Adschiri, and K. Arai, "Decomposition kinetics of 2-propylphenol in supercritical water," J. Anal. Appl. Pyrolysis, vol. 70, pp. 735-746, 2003.

[13] P. E. Savage, S. Gopalan, T. I. Mizan, C. J. Martino, and E. E. Brock, "Reactions at supercritical conditions: application and fundamentals," AIChE J., pp. 1723-1725, July, 1995.

[14] O. M. Ogunsola, "Decomposition of isoquinoline and quinoline by supercritical water," J. Hazard. Mater., vol. 74, no. 3, pp. 187-195, 2000.

[15] A. Sobhy, R. I. L. Guthrie, I. S. Butler, and J. A. Kozinski, "Naphthalene combustion in supercritical water flame," in Proc. Combustion Institute, vol. 32, 2009, pp. 3231-3238.

[16] A. Kishita, N. Watanabe, and J. V. Perez, "Observation study of the heavy crude oil dissolution behavior under supercritical condition of water," in Proc. International Petroleum Technology Conf., 2009, pp. 2921-2924.

[17] K. M. Benjamin and P. E. Savage, "Hydrothermal reactions of methylamine," J. Supercrit. Fluids, vol. 31, pp. 301-311, 2004.

[18] T. J. Houser, D. M. Tiffany, Z. Li, M. E. McCarville, and M. E. Houghton, "Reactivity of some organic compounds with supercritical water," Fuel, vol. 65, pp. 827-832, 1986.

[19] Th. Hirth and E. U. Franck, "Oxidation and hydrothermolysis of hydrocarbons in supercritical water at high pressures," Ber. Bunsen Ges. Phys. Chem., vol. 97, pp. 1091-1098, 1993.

[20] K. Arai and T. Adschiri, "Importance of phase equilibria for understanding supercritical fluid environments," Fluid Phase Equilib., vol. 158-160, pp. 673-684, 1999.

[21] H. J. Ederer, A. Kruse, C. Mas, and K. H. Ebert, "Modelling of the pyrolysis of tert-butylbenzene in supercritical water," J. Supercrit. Fluids., vol. 15, pp. 191-204, 1999.

[22] P. E. Savage, "Organic chemical reactions in supercritical water," Chem. Rev., vol. 99, pp. 603-621, 1999.

[23] Y. Ding, L. Zhao, Z. Cheng, P. Yuan, and W. Yuan, "Pyrolysis of hexadecane as model compound in supercritical water," Petrochemical Technology, vol. 35, pp. 633-637, 2006.

[24] P. C. Mandal, T. Shiraishi, Wahyudiono, M. Sasaki, and M. Goto, "Heptylbenzene decomposition in supercritical water: A simulation study," International Journal of Engineering \& Technology, vol. 7, no. 4, pp. 689-699, 2010.

[25] M. Golombok and E. Ineke, "Oil mobilization by subcritical water processing," J. Petrol. Explor. Prod. Technol., vol. 3, pp. 225-263, 2013.

[26] S. wang, Y. Guo, L. Wang, Y. Wang, D. Xu, and H. Ma, Supercritical water oxidation of coal: Investigation of operating parameters' effects, reaction kinetics and mechanism," Fuel Process. Technol., vol. 92, pp. 291-297, 2011.

[27] Y. Guo, S. Z. Wang, D. H. Xu, H. H. Ma, and X. Y. Tang, "Review of catalytic supercritical water gasification for hydrogen production from biomass," Renew. Sust. Energ. Rev., vol. 14, no. 1, pp. 334-343, 2010.

[28] H. Weingartner and E. U. Franck, "Supercritical water as a solvent," Angew. Chem. Int. Ed., vol. 44, pp. 2672-2692, 2005.

[29] T. Moriya and H. Enomoto, "Charateristics of polyethylene cracking in supercritical water compared to thermal cracking," Polym. Degrad. Stab., vol. 65, pp. 373-386, 1999. 
Pradip C. Mandal graduated from Bangladesh University of Engineering and Technology (BUET) in 1998 and received his $\mathrm{PhD}$ degree in chemical engineering from Kumamoto University, Japan in 2011. From 2001 to 2014, he worked at Titas Gas Transmission and Distribution Co. Ltd. Currently, he is a lecturer at the Department of Chemical Engineering, Universiti Teknologi PETRONAS (UTP), Malaysia.

His research interests are in heavy oil upgrading, extraction using green solvent and methane capture. Dr. Mandal is a member of IEB, IJET, and JOAE.

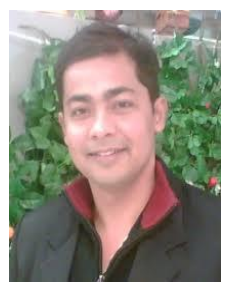

Sujan Chowdhury received his $\mathrm{PhD}$ degree in chemical engineering from Yuan Ze University, Taiwan in 2011. Currently, he is a senior lecturer at the Department of Chemical Engineering, Universiti Teknologi PETRONAS (UTP), Malaysia. His research interests are in nanomaterials, catalysis, bio-oil, and nanofluids.

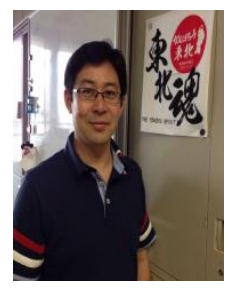

Mitsuru Sasaki was born in Iwate Prefecture in Japan on May 31, 1972. In 1995, he graduated from Biochemical Engineering Department at Tohoku University (Sendai, Japan), and Graduate School of Chemical Engineering, Tohoku University (Sendai, Japan) in March, 1997, and he received the degree of engineering from Tohoku University (Sendai, Japan) in March, 2000.

He obtained a researcher position at Genesis Research Institute, Inc. (Nagoya, Japan) in April 2000 and has worked for the development of new biomass utilization process with supercritical fluids as a joint research with Supercritical Fluids Technology Laboratory (Profs. Kunio Arai and Tadafumi Adschiri) in Tohoku University (Sendai, Japan) for three years. During this period, he also worked with students at the laboratory as a research assistant. In April 2003, he had an academic position (Assistant professor) at Department of Applied Chemistry and Biochemistry, Kumamoto University (Kumamoto, Japan) and became Associate Professor of Graduate School of Science and Technology, Kumamoto University in March 2005. He worked to create novel biomass utilization methodologies in terms of supercritical fluids and pulsed power technologies to realize an energy-saving and environmentally-benign process. In addition, he is challenging to develop new recycling/upgrading methods of heavy oils, used concrete materials and organic-inorganic hybrid materials with these technologies. In April 2013, he became an associate professor of Institute of Pulsed Power Science (IPPS), Kumamoto University. His main publication is Y. Matsumura, M. Sasaki, K. Okuda, S. Takami, S. Ohara, M. Umetsu, and T. Adschiri, "Supercritical water treatment of biomass for energy and material recovery," J. Combustion Sci. Technol., 178(1-3), 509-536, 2006. His current interests include molecular transformations of sugars, organic acids and amino acids in supercritical fluids, pulsed discharge atmosphere and under mega-gravity field to synthesize new functional materials and create novel synthesic methods in economically and environmentally friendly manners.

Dr. Sasaki is a member of the Society of Chemical Engineers, Japan (SCEJ), and The Cellulose Society of Japan. 